\title{
Portable microwave radiometer for wearable devices
}

\section{Radiómetro de microondas en miniatura para dispositivos portátiles}

\author{
Sergey G. Vesnin ${ }^{1,2 *}$, Mikhail K. Sedankin ${ }^{3,4}$, Lev M. Ovchinnikov ${ }^{2}$, Alexander G. Gudkov ${ }^{1}$, \\ Vitaly Yu. Leushin ${ }^{1}$, Igor A. Sidorov ${ }^{1}$, Igor I. Goryanin ${ }^{5}$ \\ ${ }^{1}$ Bauman Moscow State Technical University, Moscow, Russian Federation \\ ${ }^{2}$ RES Company. Moscow, Russian Federation \\ ${ }^{3}$ State Research Center - Burnasyan Federal Medical Biophysical Center of Federal Medical \\ Biological Agency. Moscow, Russian Federation \\ ${ }^{4}$ National Research University «Moscow Power Engineering Institute». Moscow, Russian Federation \\ ${ }^{5}$ University of Edinburgh. Edinburgh, United Kingdom \\ *Vesnin47@gmail.com
}

(recibido/received: 07-mayo-2021; aceptado/accepted: 10-julio-2021)

\begin{abstract}
This paper presents a new circuit of the miniature microwave radiometer for wearable devices, which can be used to monitor the core body temperature (CBT) of internal human tissues continuously 24/7. The measurement results of the proposed device, as opposed to the known miniature wearable radiometers, remain unchanged when the impedance of the examined area varies. We have derived an analytical expression for radiometer measurement error based on parameters of device components. This formula allows accuracies to be estimated and optimal parameters of the circuit to be selected to minimise measurement error at a design stage. It is shown that measurement error is independent of the antenna reflection coefficient and the temperature of the radiometer front-end. A prototype of the single-channel miniature radiometer has $32 \times 25 \times 14 \mathrm{~mm}^{3}$ dimensions and USB interface communication with PC. A 28-hour run of the device has shown that it is highly stable, and a maximum drift in temperature is $0.15^{\circ} \mathrm{C}$. Operating frequency range was $3400-4100 \mathrm{MHz}$, supply voltage $-5 \mathrm{~V}$; power supply of the radiometer in measurement mode is $210 \mathrm{~mA}$; time constant of the radiometer without being averaged is $0.6 \mathrm{sec}$, at the same time, standard deviation $\delta=0.17^{\circ} \mathrm{C}$, with further averaging during $4 \mathrm{sec} \delta=0.052^{\circ} \mathrm{C}$, with averaging during $30 \mathrm{sec} \delta=0.017{ }^{\circ} \mathrm{C}$; when there were input reflections $\mathrm{R}^{2}=0.25$, an error in measuring brightness temperature shifted by $0.2^{\circ} \mathrm{C}$; with $10^{\circ} \mathrm{C}$ variations in ambient temperature the shift was $0.15^{\circ} \mathrm{C}$. Introduction of self-contained power supply and wireless communication with smartphone have made it possible to use the proposed radiometer as a wearable device to monitor the temperature of internal tissues and CBT during human activities.
\end{abstract}

Keywords: Microwave radiometer; Circuit parameters; Miniature radiometer; Core body temperature measurement; Temperature sensors; Wearable sensors; Non-invasive passive measurement.

\section{RESUMEN}

En este trabajo se presenta un nuevo circuito para un radiómetro de microondas en miniatura para dispositivos portátiles, que puede utilizarse para controlar la temperatura de los tejidos internos humanos durante la vida. A diferencia de los radiómetros portátiles en miniatura conocidos, los resultados de las mediciones del dispositivo propuesto no cambian cuando cambia la impedancia de la zona investigada. Se obtienen las correlaciones analíticas que relacionan el error de medición del 
radiómetro con los parámetros eléctricos de los componentes del dispositivo. Esto permite estimar la exactitud prácticamente realizable en la fase de diseño y seleccionar los parámetros óptimos del circuito para minimizar el error de medición. Al elegir los parámetros óptimos del circuito, el error de medición no depende del coeficiente de reflexión de la antena ni de la temperatura de la parte de entrada del radiómetro. Hemos desarrollado un prototipo de radiómetro de un solo canal, con unas dimensiones totales de $32 \times 25 \times 14 \mathrm{~mm}^{3}$, que se comunica con el PC a través de una interfaz USB. Una prueba de duración de 28 horas demostró que el dispositivo es muy estable, con una caída de temperatura máxima de $0.15^{\circ} \mathrm{C}$, banda de frecuencia de funcionamiento $3400-4100 \mathrm{MHz}$, tensión de alimentación $5 \mathrm{~V}$, el consumo de energía del radiómetro en el modo de medición es de $210 \mathrm{~mA}$ a $5 \mathrm{~V}$, la constante de tiempo del radiometro sin promediar es de $0,6 \mathrm{seg}$, con una desviación estándar $\delta=$ $0,17^{\circ} \mathrm{C}$, con un promedio adicional de 4 segundos $\delta=0,052^{\circ} \mathrm{C}$, con un promedio de 30 seg. $\delta=0,017^{\circ}$ $\mathrm{C}$, en presencia de reflejos en la entrada $\mathrm{R}^{2}=0.25$, el error de medición de la temperatura de brillo de radio fue de $0,2^{\circ} \mathrm{C}$, el error de medición fue de $0,15^{\circ} \mathrm{C}$, cuando la temperatura del gabinete se modificó en $10^{\circ} \mathrm{C}$. Tras introducir una fuente de alimentación autónoma y una comunicación inalámbrica con un smartphone, el radiómetro propuesto puede utilizarse como dispositivo portátil para controlar la temperatura de los tejidos internos durante la vida humana.

Palabras clave: Términos del Índice Radiómetro de microondas; Parámetros del circuito; Radiómetro en miniatura; Medición de la temperatura; Sensores de temperatura; Sensores portátiles; Medición pasiva no invasiva.

\section{INTRODUCTION}

There is a growing interest from medical specialists in using passive microwave radiometry. In particular, microwave radiometers have been used in several fields of medicine to:

- detect breast cancer and monitor the effectiveness of the administered treatment (Vesnin, Turnbull, Dixon and Goryanin, 2017; Goryanin, et al., 2020),

- examine carotid arteries to reveal inflamed atherosclerotic plaques and patients with a high risk of stroke (Toutouzas, et al., 2017; Drakopoulou, et al., 2018),

- measure the brain temperature (Groumpas, et al., 2019; Kublanov, Borisov, 2017; Gudkov, et al., 2019), both in treatment of stroke and traumatic brain injuries (Cheboksarov, et al., 2015),

- monitor the brain temperature during hypothermia (Rodrigues, et al., 2018),

- diagnose inflammatory joint diseases (Laskari, et al., 2020; Ravi, Sharma and Arunachalam, 2019),

- diagnose vesicoureteral reflux in children (Arunachalam, et al., 2011; Jacobsen, Klemetsen and Birkelund, 2012),

- evaluate the activity of brown adipose tissue (Crandall, et al., 2018),

- $\quad$ assess intensity of backpain (Tarakanov and Goryanin, 2020).

In most of these works, stationary microwave radiometers like RTM-01-RES (Vesnin, Turnbull, Dixon and Goryanin, 2017) were used to measure the temperature of internal tissues. Unfortunately, such devices cannot be used to monitor the temperature during human vital activities. There is a great demand for such devices, and there are recent papers on the development of miniature wearable radiometers, which can be mounted on the human body for dynamic monitoring of CBT internal temperatures (Momenroodaki, 2018; Stauffer, et al., 2013; Haines, et al., 2017; Popovic, Momenroodaki, and Scheeler, 2014; Momenroodaki, Haines and Popovic, 2017; Ravi and Arunachalam, 2019; Maccarini, Shah, Palani, et al., 2015; Groumpas, Koutsoupidou, Karanasiou, Papageorgiou and Uzunoglu, 2019). It is especially important for estimation of the temperature of various organs when exposed to functional loads. In general, these works use the concept of total power radiometer and two embedded noise sources - Cold Source and Hot Source. Such a concept has been previously applied to radiometers used to measure soil moisture, identify fire seats, monitor pollution in the ocean, etc. (Goodberlet and Mead, 2006; Ulaby and Long, 2014). This approach 
enabled scientists to design compact medical radiometers (Momenroodaki, 2018; Stauffer, et al., 2013; Haines, et al., 2017; Popovic, Momenroodaki, and Scheeler, 2014; Momenroodaki, Haines and Popovic, 2017; Ravi and Arunachalam, 2019; Maccarini, Shah, Palani, et al., 2015; Groumpas, Koutsoupidou, Karanasiou, Papageorgiou and Uzunoglu, 2019; Livanos, Hammal, Nikolopoulos, et al., 2018). For example, a microwave radiometer described in (Momenroodaki, 2018) measures $82 \mathrm{~mm}$ x $50 \mathrm{~mm}$. In (Stauffer, et al., 2013), it has been noted that the designed radiometer excels in a remarkably high stability and can be applied to monitor the brain temperature. In (Haines, et al., 2017), a wireless radiometer, functioning in the frequency range of $1400-1427 \mathrm{MHz}$ has been presented. A distinguishing feature of the referenced radiometers is that no nonreciprocal elements are used in their input section to decouple antenna and amplifiers. This structure allows a noise signal from the antenna output to directly enter the low-noise amplifier. If the antenna is well-matched with a measured biological object, a reflection coefficient $\Gamma^{2}$ is zero, and the noise signal $T_{r 1} \Gamma^{2}$ enters the radiometer input without attenuation.

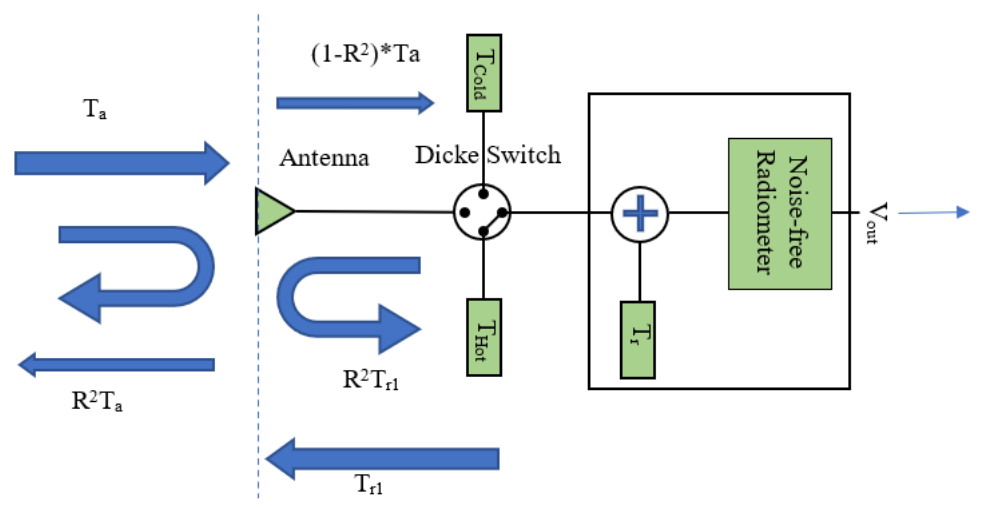

Figure 1. Block diagram of the radiometer front-end

If there are reflections, in addition to the noise signal from the antenna, the noise signal $T_{r 1} \Gamma^{2}$ also enters the radiometer input. This signal originates from the radiometer front-end, enters the antenna on the side of the radiometer, is reflected off the antenna and goes back to the device input (Fig.1).

$$
\begin{aligned}
& T_{i n}=T_{a}\left(1-\Gamma^{2}\right)+T_{r 1} \Gamma^{2} \\
& T_{r 1}=T_{r} * K_{l}+\alpha_{l} * T_{a m b}
\end{aligned}
$$

$\alpha_{l}-$ cable and switch losses

$T_{r}$ - noise temperature of low noise amplifier

$\Gamma^{2}$ - antenna reflection coefficient

$$
K_{l}=1-\alpha_{l}
$$

If there are no reflections off the antenna $\left(\Gamma^{2}=0\right)$, noise signal $T_{a}$ enters the radiometer input

$$
T_{\text {in }}=T_{a}
$$

However, it is hard to ensure good match between antenna and various parts of the human body, since dielectric permittivity of human tissues varies at different points. Moreover, dielectric permittivity of different body parts of different people may vary significantly. Hence, with a good match at one point, there can be a considerable reflection at the other. 
To reduce the effect of the antenna reflection, a circulator is mounted between LNA and antenna. The circulator has three signal paths that we will denote hereinafter: input arm, output arm and balance arm. Hence balance arm is loaded with matched resistive load, the circulator will not pass signal from output arm to input arm. Then, the noise temperature of the radiometer input section $T_{r 1}$ should be close to the temperature of the balance arm load. If the temperature of balance arm load is close to Ta, then according to equation (1), the measurement error resulting from the antenna reflection is minor.

In some radiometers, the balance resistor is heated to make its temperature close to the temperature Ta. It follows from equation (1) that in this case reflections from the antenna have no effect on measurement results. For example, such a circuit is used in commercial radiometer (Vesnin, Turnbull, Dixon and Goryanin, 2017; Goryanin, et al., 2020), which was employed to diagnose stroke risk (Toutouzas, et al., 2017; Drakopoulou, et al., 2018), in neurology (Goryanin, et al., 2020), urology (Kaprin, et al., 2019), mammology/breast care (Vesnin, Turnbull, Dixon and Goryanin, 2017), to measure the brain temperature (Cheboksarov, et al., 2015), to measure self-radiation of enzymes and malignant cells in the microwave range (Ivanov, et al., 2018; Ivanov, et al., 2019), in experimental oncology to measure the temperature of malignant tumour in mice (Zinovyev, n.d.). However, this appliance is rather bulky and cannot be used in wearable devices.

\section{MATERIALS AND METHODS}

The authors propose a portable microwave radiometer for wearable devices that has a reflection coefficient, the variations in which have minor effect on measurement results. The block diagram of the device is given in Fig.2.

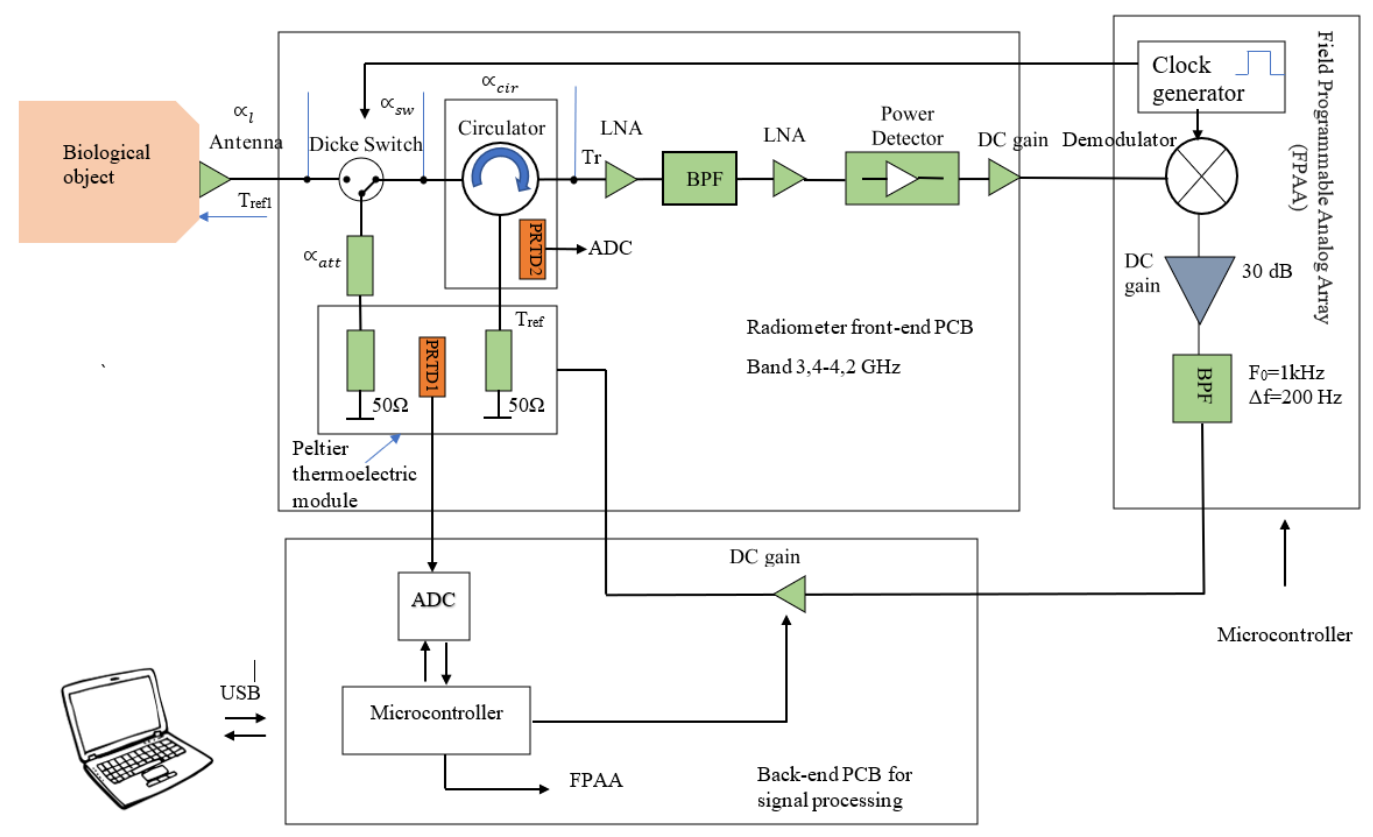

Figure 2. Block diagram of miniature microwave radiometer $\mathrm{BPF}$ - band-pass filter; PRTD - platinum resistance temperature detector

The structure has significant similarities with Dicke radiometer. The Single Pole Double Throw (SPDT) switch in the proposed circuit connects either antenna, or reference noise source to the receiver. The reference noise source in the suggested circuit is a matched load mounted on the Peltier element, which can change its temperature depending on the control voltage. This control voltage is wired to output signal of synchronous detector, which is proportional to the difference between 
reference $T_{\text {ref }}$ and measured Ta temperatures. When the feedback is negative, the voltage at the output of synchronous detector approaches zero, and the matched load temperature approaches Ta. The temperature sensor is placed to measure the absolute temperature of the Peltier element. Since we can substitute absolute temperature for noise temperature if load is matched, we can expect that this temperature is equal to measured temperature Ta.

A special feature of the proposed circuit is that in addition to the reference noise source, the balance arm resistive load is mounted on the same Peltier element, so the temperature of both loads is equal to $T_{\text {ref }}$. An attenuator with the absolute temperature Tamb and attenuation $K_{\text {att }}=\left|S_{12}\right|^{2}$ is also mounted between the reference noise source $T_{r e}$ and the switch. When the SPDT switch is connected to the antenna, the voltage at the amplitude detector output will be determined by the following equations (57)

$$
\begin{gathered}
V a 1=\left(\left(T a *\left(1-\Gamma^{2}\right)+\Gamma^{2} T_{r e f 1}\right) * K_{s}+\propto_{s} \operatorname{Tamb}+T r\right) \\
K_{s}=K_{s w} * K_{c i r} * K_{l} \\
\propto_{s}=1-K_{s}
\end{gathered}
$$

$\propto_{s}$ is total losses, including losses in the SPDT switch, circulator and coaxial cable, connecting antenna and radiometer,

$T a m b$ is temperature of the radiometer front-end,

$G$ is gain factor of the path,

$\operatorname{Tr}$ is noise temperature at the low noise amplifier input,

$K_{\text {sw }}, K_{\text {cir }}, K_{l}$ are attenuation of switch, circulator and coaxial cable.

In the other switch mode, the signal from the circulator balance load with temperature $T_{\text {ref }}$ enters the antenna on the side of the radiometer. Taking losses into consideration, the noise temperature at the antenna input will be defined using equation (6).

$$
T_{\text {ref } 1}=T_{\text {ref }} * K_{s}+\propto_{s} T a m b
$$

If the noise signal comes from the matched load with temperature $T_{\text {ref }}$, the voltage at the amplitude detector output will be determined by equations (9-11) (provided that for the matched load $R^{2}=0$ ):

$$
\begin{gathered}
V a 2=\left(T_{\text {ref }} * K_{t}+\propto_{t} * T a m b+T r\right) * G \\
K_{t}=K_{s w} * K_{\text {cir }} * K_{\text {att }} \\
\propto_{t}=1-K_{t}
\end{gathered}
$$

where $K_{a t t}$ is attenuator loss.

The goal condition is: 
which can be achieved by changing Tref.

We deduce the value $T_{\text {ref }}$ so the equation (12) is satisfied from equations (5-11):

$$
\begin{gathered}
\text { Ta }=T_{\text {ref }} * K+(1-K) \text { Tamb } \\
T_{\text {ref }}=k k * T a+(1-k k) * \text { Tamb } \\
K=K_{s} \frac{\left(U-\Gamma^{2}\right)}{1-\Gamma^{2}} \\
U=\frac{K_{t}}{K_{s}^{2}} \\
k k=\frac{1}{K} \\
\text { When } U=1 \\
K=K_{s} \quad T T_{\text {ref } 1}=T a
\end{gathered}
$$

It follows from equation (5) that if $T_{\text {ref } 1}=T a$, the measurement results are independent of the antenna reflection coefficient.

Varying attenuation $K_{\text {att }}$ it is possible to minimise the effect of the antenna reflection coefficient on the measurement error.

Equations $(18,6,10)$ allow finding the value of attenuator loss such that measurement results are independent of the reflection coefficient.

$$
K_{\text {att opt }}=K_{s} * K_{l}
$$

It follows from equations $(13-14)$ that if condition $V a 2=V a 1$ is met, and the temperatures of the radiometer input section Tamb and matched load Tref are measured, one can calculate Ta from the equation (13). Here, the result will not depend on the antenna reflection coefficient, if the attenuator loss satisfies the equation (19).

Unfortunately, it is not always possible to accurately choose the optimal value of attenuator loss, hence, it is important to understand, what kind of error will occur at the random value of attenuation. In this effort, let's analyse process of the device calibration.

Let the temperature measured by the radiometer $T a_{m}$ be written as follows:

$$
T a_{m}=H * T r e f+\alpha_{r d} T a m b+b
$$


$H, k_{r d}, b-$ coefficients to be defined during calibration.

It is assumed in equation (20) that the temperature of the cable connecting antenna and radiometer is the same as the temperature Tamb. If they differ, coefficient $\alpha_{\mathrm{c}}$ and Tamb cable should be added to equation (20).

To determine $H$ and $b$ in the course of calibration, the temperatures $\operatorname{Tref}_{1} \operatorname{Tref}_{2}$ at the two noise temperature values shall be measured. If $T_{2 \text { ref }}$ and $T_{1 \text { ref }}$ Tamb remain unchanged when being measured, the calibration coefficients will be defined by the following expression

$$
\begin{gathered}
H=\frac{T_{2 r e f}-T_{1 r e f}}{T_{a 2}-T_{a 1}} \\
b=T a_{2}-T_{2 r e f} * H-\alpha_{r d} T a m b
\end{gathered}
$$

Let's analyse the dependence of calibration coefficients on losses in circuit elements. While calibrating, both the antenna and the radiometer input are matched with a calibration setup, therefore, we assume $\Gamma^{2}=0$.

Here, from equations (15-16), when $\Gamma=0$, it follows that

$$
K=K_{0}=\frac{K_{t}}{K_{s}}
$$

Taking into account (6) and (10)

$$
K_{0}=\frac{K_{\text {att }}}{K_{l}}
$$

Putting expressions (13) and (20) together,

$$
\begin{gathered}
H=K_{0} \\
\alpha_{r d}=1-K_{0} \\
T a_{m}=K_{0} * \text { Tref }+\left(1-K_{0}\right) \text { Tamb }
\end{gathered}
$$

From equation (13), taking into account $(14,25-27)$, the formula for calculating the radiometer error can be deduced:

$$
\Delta T=\left(T a-T a_{m}\right)=(T a-T a m b) * \Gamma u^{2}
$$




$$
\begin{gathered}
\Gamma u^{2}=\left(1-\frac{K_{0}}{K}\right)=\Gamma^{2}\left(\frac{U-1}{U-\Gamma^{2}}\right) \\
T a_{m}=\left(1-\Gamma u^{2}\right) T a+T a m b * \Gamma u^{2}
\end{gathered}
$$

$T a_{m}$ - temperature measured by radiometer

$T a$ - brightness temperature of a biological object.

Accuracy of the described radiometer at an arbitrary value of the $\Gamma^{2}$ coefficient, at various values of the radiometer parameters $K_{s w}, K_{\text {cir }}, K_{l}, K_{\text {att }}$ and random temperature of the radiometer input section Tamb can be computed using expressions (28-29). Formula (30) allows computing the temperature measured by the radiometer if the sensor input section temperature Tamb varies.

The use of the above-mentioned procedure makes it possible to obtain the similar expression to calculate an error of brightness temperature for the conventional configuration of the Dicke radiometer. For the Dicke radiometer, the coefficients in equation (28-30) are defined by equations $(31,32)$.

$$
\begin{gathered}
\Gamma u^{2}=\Gamma^{2} \\
K_{0}=\frac{K_{t}}{K_{s}}
\end{gathered}
$$

The brightness temperature measurement error is determined by expression (28).

\section{RESULTS OF CALCULATIONS}

Fig. 3 presents the dependence of the error in measuring brightness temperature for various values of the antenna VSWR on the attenuator loss. The calculations were made using equation (28).

It follows from Fig. 3 that the proposed circuit has the optimal value of attenuator loss such that the error in measuring brightness temperature equals to zero, irrespective of the antenna reflection coefficient. If the difference between the attenuator loss and its optimal value is less than $0.5 \mathrm{~dB}$, the error in measurement is not greater than $0.26 \mathrm{C}$ at the antenna VSWR of $3\left(\Gamma^{2}=0.25\right)$. This value is fairly good, taking into account that in this case the radiometer input receives $25 \%$ less power, with that the error in measuring power in relative units is $0.083 \%$.

Clearly, in operation the device heats up due to a heating system, and the temperature Tamb may vary, what causes an additional measurement error. Fig. 4 presents the dependence of the error in measuring brightness temperature on the temperature Tamb for various attenuator losses. 


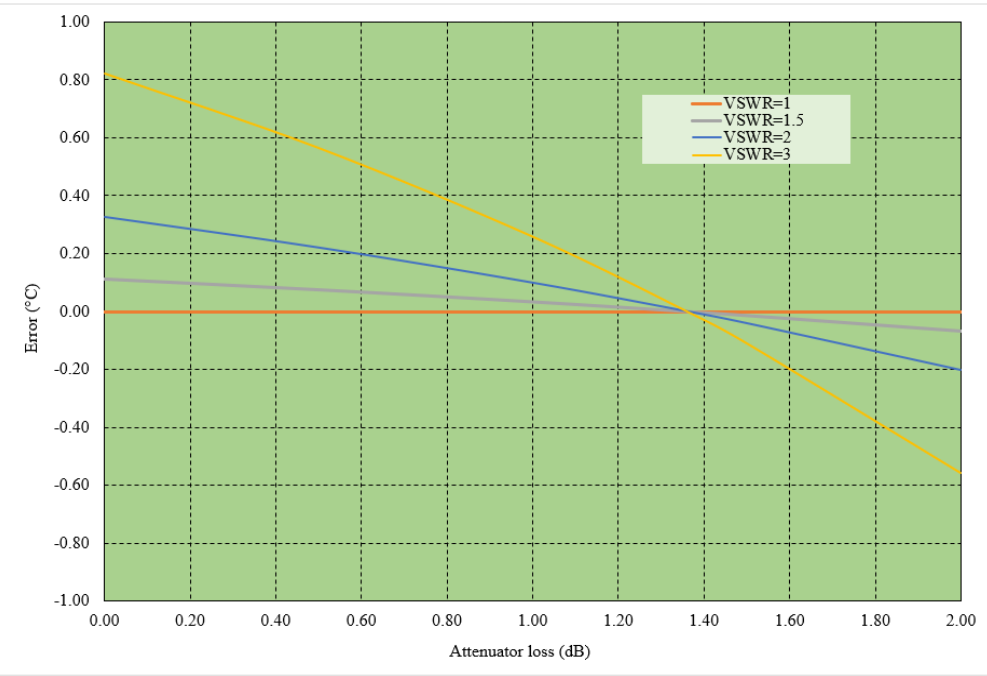

Figure 3. Dependence of the error in measuring brightness temperature $\Delta T=T a-T a_{m}$ for different values of the antenna VSWR on attenuator loss Ta-Tamb $=10{ }^{\circ} \mathrm{C} \propto_{l}=0.1 \mathrm{~dB} \propto_{s W}=0.5 \mathrm{~dB}$

$$
\propto_{\text {cir }}=0.66 \mathrm{~dB} \quad \propto_{\text {att opt }}=1.36 \mathrm{~dB}
$$

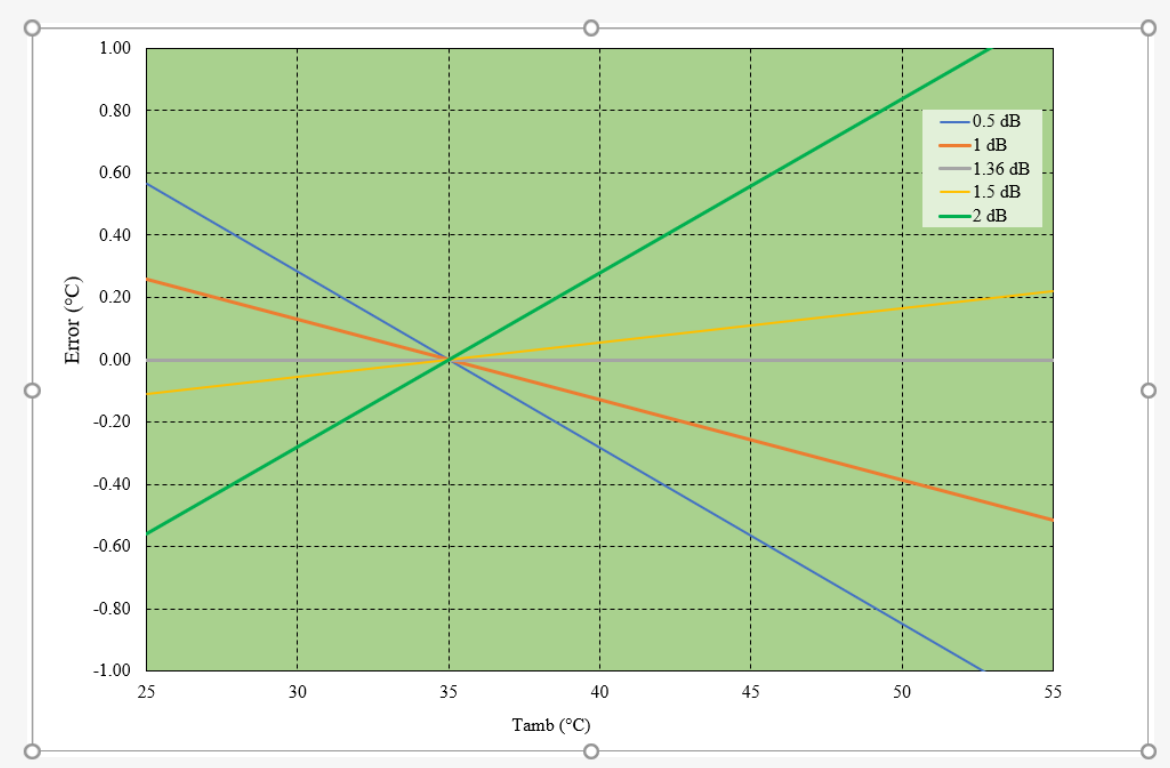

Figure 4. Dependence of the error in measuring brightness temperature $\Delta T=T a-T a_{m}$ on temperature $T a m b$ for different values of attenuator loss $\mathrm{Ta}=35^{\circ} \mathrm{C} . \propto_{l}=0.1 \mathrm{~dB} \propto_{s w}=0.5 \mathrm{~dB} \propto_{c i r}=0.66 \mathrm{~dB}$

$$
\propto_{\text {att opt }}=1.36 \mathrm{~dB}
$$

It follows from Fig.4 that if Tamb is close to Ta, the effect of the antenna reflection coefficient on measurement results reduces. When the value of attenuator loss is optimal (here, it is equal to $1.36 \mathrm{~dB}$ ), the error in measuring brightness temperature is zero, irrespective of the antenna reflection coefficient and Tamb. At $\propto_{\text {att }}=1 d B$ and VSWR=2, Tamb varies within $\pm 5 \mathrm{C}$, and an error grows to $0.05^{\circ} \mathrm{C}$.

Fig.5 presents the dependence of the radiometer measurement error on the antenna VSWR for different values of the attenuator loss. 


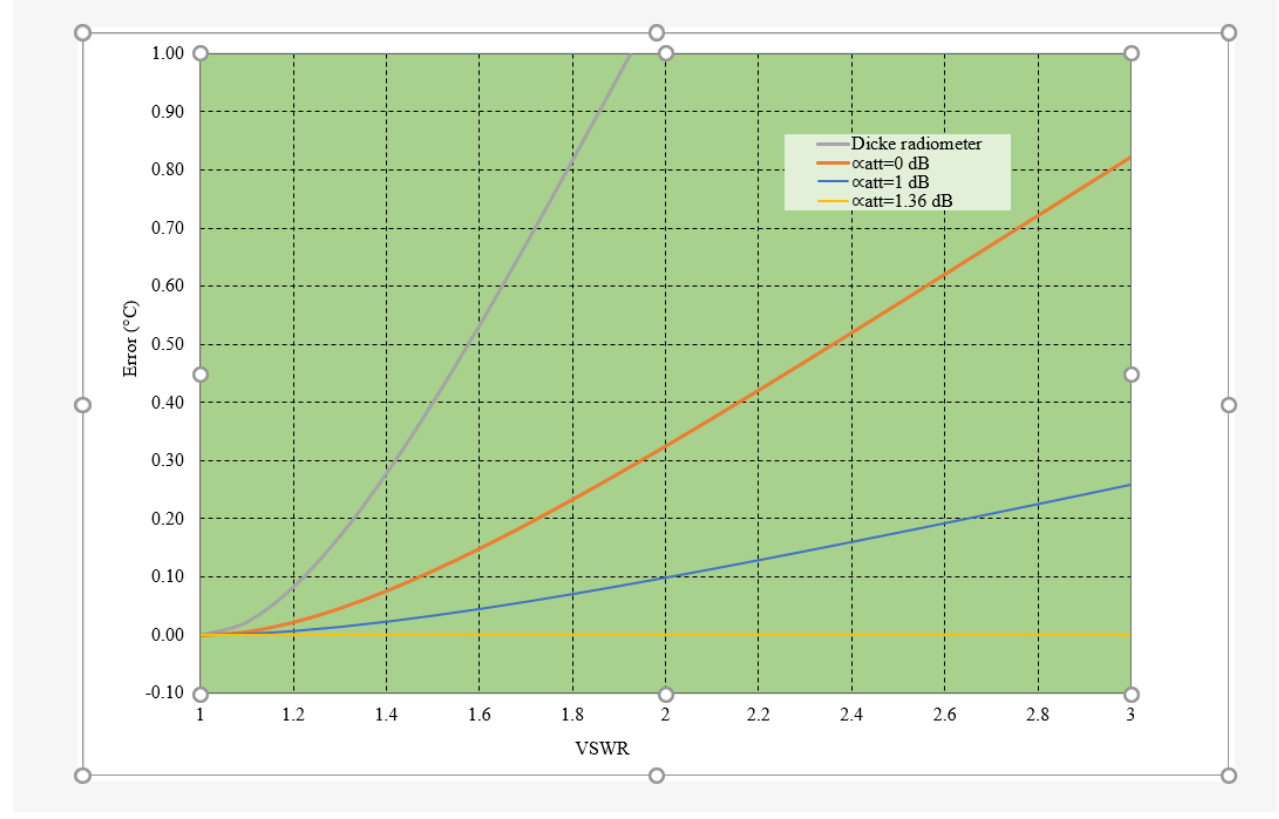

Figure 5. Dependence of the error in measuring brightness temperature $\Delta T=T a-T a_{m}$ on the antenna VSWR for different values of attenuator loss $\propto_{l}=0.1 \mathrm{~dB} \quad \propto_{s w}=0.5 \mathrm{~dB} \quad \propto_{c i r}=0.66 \mathrm{~dB}$ $\propto_{\text {att opt }}=1.36 \mathrm{~dB} \quad(\mathrm{Ta}-\mathrm{Tamb})=10^{\circ} \mathrm{C}$

For comparison, this graph presents the curve obtained for the Dicke radiometer along with the curve, obtained when the attenuator loss was zero. The graph clearly demonstrates that the use of the proposed circuit with two loads mounted on the Peltier element allows the device measurement error to be significantly reduced. The introduction of an additional attenuator into the circuit of the reference noise source also makes it possible to minimise the effect of the antenna reflection coefficient on measurement results.

\subsection{Pilot studies}

A radiometer front-end was implemented by printed circuitry-based methods with the use of the $\mathrm{RO} 4003 \mathrm{C}$ material of dielectric permittivity $\mathrm{e}=3.38$ and thickness $3.05 \mathrm{~mm}$. The front-end module block diagram is marked off by the continuous line in Fig.2. A two-stage low noise amplifier is implemented using "Avago Technologies VMMK-3803" LNA, with a noise coefficient of $1.9 \mathrm{~dB}$. The total gain of the two-stage LNA is $46 \mathrm{~dB}$. A 4-resonator filter of the "RES Company" with attenuation poles at finite frequencies due to a parallel-cascade connection of resonators (Zinovyev, n.d.) was utilised as a band pass filter (BPF). The filter is implemented on a substrate with high dielectric permittivity $(\mathrm{e}=100)$. Overall dimensions of the filter dielectric base are $4 \times 4 \times 0.5 \mathrm{~mm}^{3}$. The noise band of the filter within the amplifier range is approximately $460 \mathrm{MHz}$. The amplifier was placed in a separate shielded compartment. Overall dimensions of the amplifier are $20 \times 11 \times 5 \mathrm{~mm}^{3}$. The "Ferrite Quasar 3CMM41-3" circulator has 0.6 dB losses and 17-20 dB decoupling in the operating frequency range. A tiny "Tyco Electronics MASW-007107" microcircuit was used for the SPDT switch. An amplitude detector is implemented based on the HSMS-286C microcircuit made by the "Avago Technologies". The source of the reference noise signal has dimensions $2 \times 2 \mathrm{~mm}^{2}$, is made as a matched load, positioned on the thermoelectric module (the Peltier element) "RMT IMD02-024-05". The circulator load is placed on the same base. The load is connected to a printed board by golden wires to reduce heat losses through connections. To prevent electromagnetic interference, the whole front-end module is placed in the electro-pressurised section, and all control signals and supply voltage are delivered to the module through low pass filters (LPFs). The front-end module has dimensions $20 \times 30 \times 5 \mathrm{~mm}^{3}$. The device has two temperature sensors. One sensor measures the 
temperature of the load, installed on the thermoelectric module. The second sensor measures temperature Tamb. The "Honeywell 702-102BBB-A00" microcircuit is used as a temperature sensor.
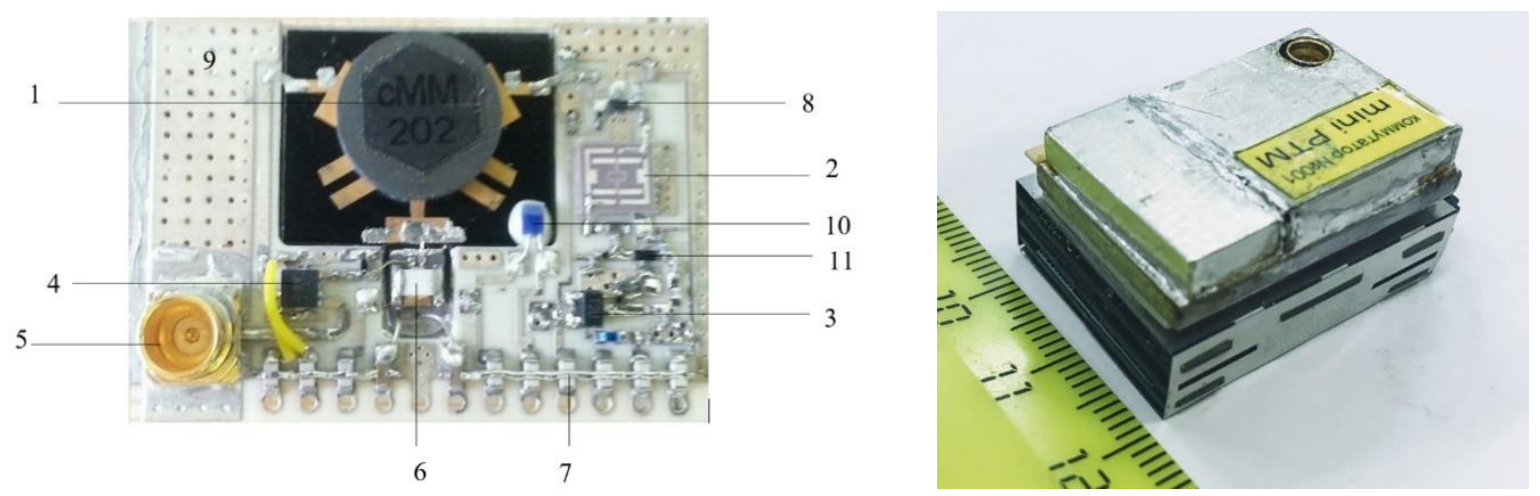

Figure 6. SPDT-module of radiometer (at the left): 1 - circulator, 2 - BPF, 3 - Power detector, 4 - SPDT switch, 5 - SPDT-connector, 6 - thermoelectric module, 7 - LPF, 8, 11 - LNA, 9 - radiometer board, 10 - temperature sensor; miniature radiometer (at the right)

Clock source, demodulator, selective amplifier, and delay line are implemented on the Field Programmable Analog Arrays (FPAA) "Anadigm AN231E04". This microcircuit operates with an analogue signal but makes it possible to vary the parameters with a digital control. The clock source operates at a frequency of $1 \mathrm{kHz}$, the selective amplifier band is $200 \mathrm{~Hz}$. The signal from the temperature sensor enters an 8-channel ADC "Analog Devices AD7194BCPZ". The "Microchip PIC18F46J50" is used as a head microcontroller, which controls device operation modes, processes the information from ADC, controls FPAA and operates PC communication by a USB interface. Several versions of the low frequency part of the module were made. One design option involved placement of the LF part on three boards of dimensions $31 \times 23 \mathrm{~mm}^{2}$, with the boards positioned stack-wise (Fig.7). The total height of the three boards is $8 \mathrm{~mm}$. Here, overall dimensions of the entire radiometer are $23 \times 31 \times 15 \mathrm{~mm}^{3}$. The other design incorporated all the device low frequency part located on one board. In this case, the radiometer dimensions are $60 \times 45 \times 12 \mathrm{~mm}^{3}$. The first option is more compact, but the device reliability depends on the reliability of board-to-board connectors. Moreover, it is more difficult to ensure heat removal from an object and inspect an object due to a restricted access to some boards. The second option allows a much easier adjustment. The electric parameters of both designs are comparable. A printed antenna was used, made of the RO4003C material, $1.27 \mathrm{~mm}$ thick, with dielectric permittivity of 10.4 . The antenna diameter is $24 \mathrm{~mm}$, the height is $5 \mathrm{~mm}$. The antenna configuration is similar to that presented in (Vesnin, et al., 2019).

\subsection{Experimental studies}

A noise generator $(\mathrm{NG})$ is used to calibrate the prototype. Noise generator consists of a matched load, heated to the fixed temperature adjustable with an accuracy of $0.01{ }^{\circ} \mathrm{C}$. Calibration of the noise generator was performed in a temperature-regulated bath with the use of the high-precision mercury thermometer that measures water temperature with an accuracy of $0.01^{\circ} \mathrm{C}$. The maximum drift in the heated resistor temperature, while the noise generator was observed during $36 \mathrm{~h}$, was no more than $0.05^{\circ} \mathrm{C}$ with standard deviation $\delta=0.023^{\circ} \mathrm{C}$. In the course of the radiometer calibration, it was first set to $38{ }^{\circ} \mathrm{C}$, and then $32^{\circ} \mathrm{C}$ was set there several seconds later. Calibration coefficients were computed by formulas $(21,22)$, the brightness temperature, measured by the radiometer, is calculated by formula (27). At the first stage, a radiometer was used without additional attenuator in the circuit of reference source $\left(\propto_{\text {att }}=0 d B\right)$ and $\propto_{l}=0 d B$.

Fig. 7 presents the time dependence of the heated resistor temperature and measured temperature, at the two values of noise signal. 


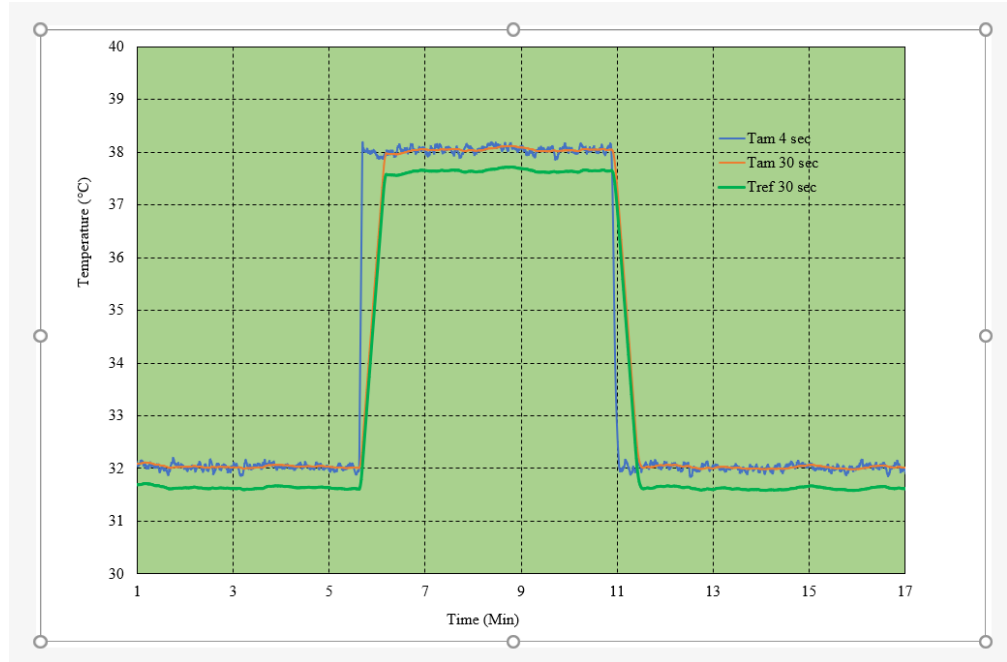

Figure 7. Time dependence of the heated resistor temperature and computed brightness temperature $T a_{m}$ at two values of noise signal $\left(32^{\circ} \mathrm{C}\right.$ and $\left.38^{\circ} \mathrm{C}\right)$, at $\mathrm{H}=1, \mathrm{~b}=0.4, \mathrm{k}=0$

It follows from the conducted test that the experimentally measured coefficient $\mathrm{H}$ is equal to 1 , what corresponds to formula (21). The experimentally found value $\mathrm{b}=0.4^{\circ} \mathrm{C}$ is nonzero, due to the error of temperature sensors, noise generator, etc. Standard deviation $(\delta)$ of the measured temperature during $200 \mathrm{sec}$ with averaging during $4 \mathrm{sec}$ is $0.052^{\circ} \mathrm{C}$, and it is $0.0167^{\circ} \mathrm{C}$ with averaging during $30 \mathrm{sec}$. This value is in agreement with the computations using the Dicke formula and is close to the results for certified stationary radiometers.

To assess the stability of the brightness temperature measurement results, the measured temperature was monitored during $28 \mathrm{~h}$. The noise generator served as a noise signal source, as in the previous experiment. Coefficient $\mathrm{H}=1$ was obtained during calibration. Thermal compensation coefficients were selected so that $T a_{m}$ remains unchanged when Tamb varies.

Fig. 8 presents the time dependence of brightness temperature.

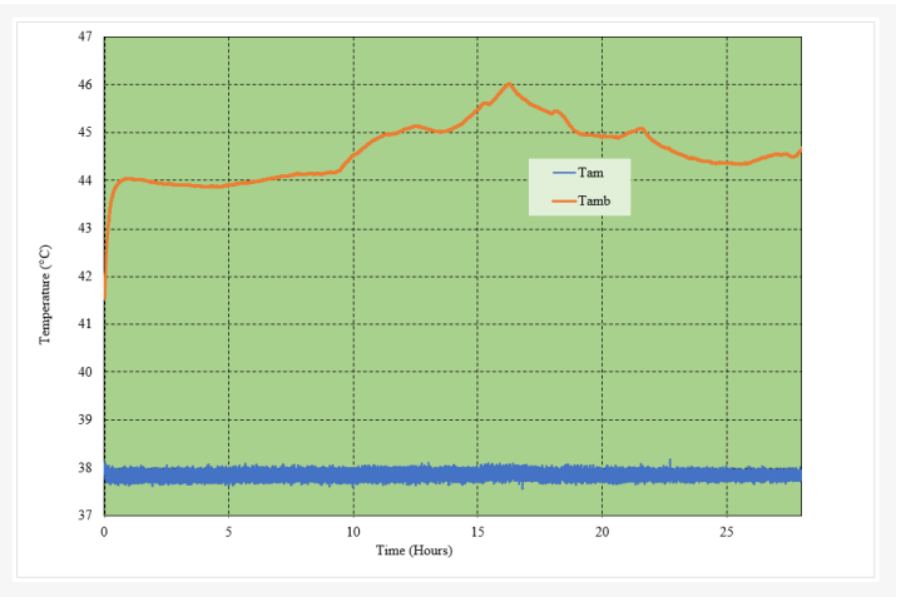

Figure 8. Experimental time dependence of brightness temperature and Tamb

Aside from brightness temperature, temperature Tamb is shown on the plot. According to the plot, the presented radiometer is quite stable. Standard deviation within $28 \mathrm{~h}$ observation is $0.058^{\circ} \mathrm{C}$ with the averaging time of $4 \mathrm{sec}$. There were no significant changes in the measured temperature because of slow changes in temperature Tamb in the range of $4^{\circ} \mathrm{C}$. 
To analyse how the measured temperature changes when Tamb varies more significantly and quickly, the following experiment was conducted. The noise signal from NG with a fixed noise temperature was sent to the radiometer input. At the first stage, the radiometer was covered with the fabric, which prevented the unit from cooling, then, this fabric was removed, and an intense cooling of the device was initiated. The room temperature was constant and equal to $26^{\circ} \mathrm{C}$. The brightness temperature was computed by formula (27) as in the previous experiment.

To assess the Tamb effect, the authors decreased the fluctuation error by increasing the time of averaging to $30 \mathrm{sec}$, what made it possible to reduce the standard deviation of the measured temperature $(\delta)$ to $0.025^{\circ} \mathrm{C}$.

Fig.9 presents the time dependence of the internal temperature and Tamb.

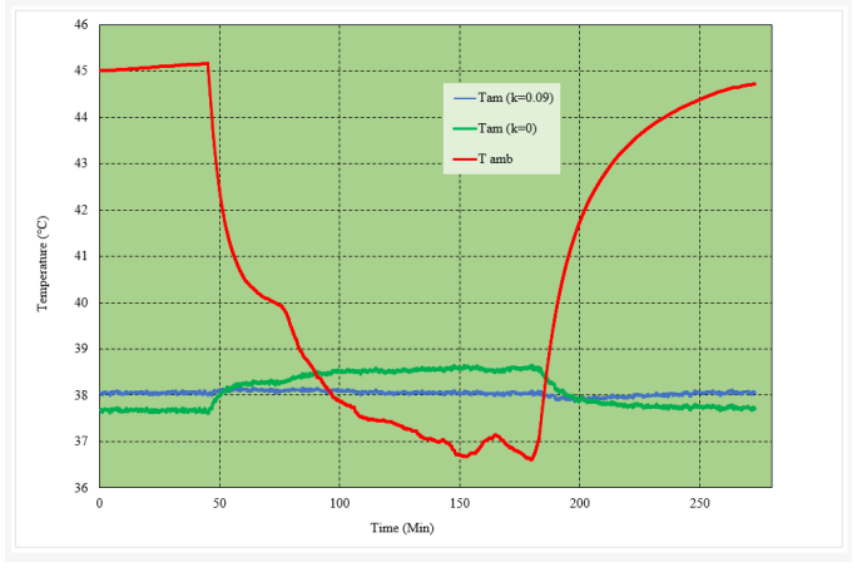

Figure 9. Experimental time dependence of brightness temperature/Tamb

It follows from the plot that, when there is no thermal compensation $(\mathrm{k}=0)$, a change in Tamb by $9^{\circ} \mathrm{C}$ causes a change in the brightness temperature by $0.9^{\circ} \mathrm{C}$. When $\mathrm{k}=0.09$ the change in the brightness temperature did not exceed $0.2 \mathrm{C}$.

Fig.10 presents the results of monitoring radiometric temperature in a water bath within $8 \mathrm{~h}$.

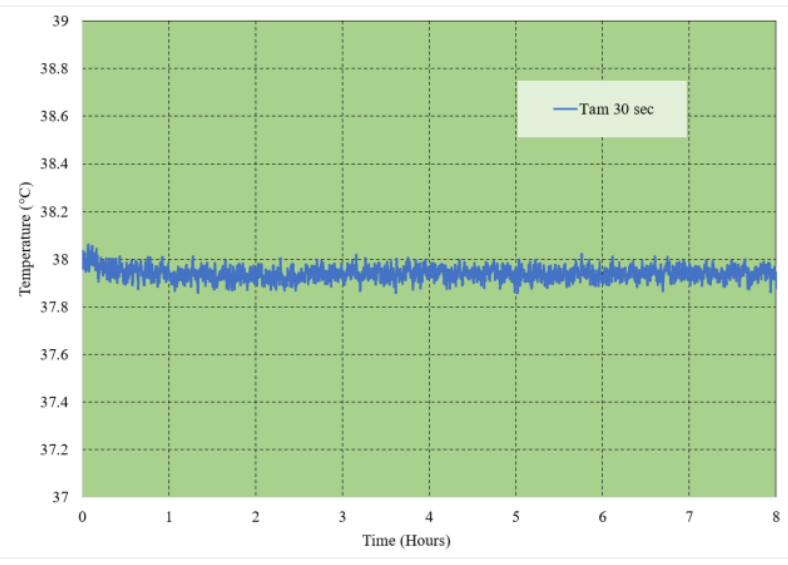

Figure 10. Time dependence of the brightness temperature

A "Huber" circulating water bath was used to carry out the experiment. The radiometer was previously calibrated according to the above-stated procedure. The water temperature in the bath was equal to $38^{\circ}$ $\mathrm{C}$ and maintained constant with an accuracy of $0.1^{\circ} \mathrm{C}$. Within 8 hours, the radiometer readings decreased by $0.1^{\circ} \mathrm{C}$. 
To assess the effect of reflection on measurement error, the following experiment was carried out. The noise signal from the noise generator with a fixed temperature of $32^{\circ} \mathrm{C}$ was sent to the calibrated radiometer input. The temperature of matched resistor $\mathrm{T}_{\text {ref }}$ was measured, and the brightness temperature was computed by formula (27). Then, a mismatch component was mounted between NG and radiometer. It is designed as a series connection of three pieces of coaxial cable with air filling. The impedance of the first and the second cable pieces is equal to $50 \mathrm{Ohm}$. The diameter of the second piece was selected so that $\Gamma^{2}$ in the operating frequency range is close to 0.25 . The length of a piece with reduced impedance was $10 \mathrm{~mm}$. Table 1 presents the results of measuring the temperature with and without mismatch component. The temperature $\mathrm{Tamb}=40^{\circ} \mathrm{C}$.

Table 1. Results of measuring the temperature with and without mismatch component

\begin{tabular}{|c|c|c|c|c|}
\hline$\propto_{\text {att }} d B$ & $\begin{array}{l}\text { NG temperature } \\
(\mathrm{C})\end{array}$ & $\begin{array}{l}\mathrm{Ta}_{m} \text { without } \\
\text { mismatch } \\
\text { component }(\mathrm{C})\end{array}$ & $\begin{array}{l}T a_{m} \text { with mismatch } \\
\text { component } \\
\left({ }^{\circ} \mathrm{C}\right)\end{array}$ & $\begin{array}{l}\text { Error } \\
\Delta T(\mathrm{C})\end{array}$ \\
\hline 0 & 38 & 38 & 37.3 & -0.7 \\
\hline 1 & 38 & 38 & 37.8 & -0.2 \\
\hline
\end{tabular}

The experiment results demonstrate that even at a relatively high reflection coefficient, the proposed radiometer circuit ensures satisfactory compensation of reflections if the attenuator value is properly chosen.

\section{DISCUSSION}

It is obvious that the use of Field Programmable Analog Arrays substantially reduces the radiometer dimensions. The circuitry aside the front-end and detection is folded into a single microcircuit.

One more aspect is that the module adjustment is made on PC after the final assembly. Specifically, gain factor of the path, time constant, and almost all the circuit parameters can be changed. Even dynamic variations in the circuit parameters are possible in the course of operation, however, the authors have not yet taken this opportunity. The second important step in reducing the radiometer dimensions is the creation of miniature filters with attenuation poles at finite frequencies and use of materials with high dielectric permittivity.

We assume that radiometers that use matched load installed on the Peltier element as a noise signal source, are low speed and can be used to monitor slow temperature changes. Indeed, the time constant of a load with dimensions $0.32 \times 0.4 \mathrm{~mm}^{2}$, is $3.2 \mathrm{sec}$. Nevertheless, in (Osipenkov and Vesnin, 1994), it has been shown that the time constant considerably reduces due to a feedback path, and the time constant in the proposed device, without additional averaging lowered to $0.6 \mathrm{sec}$, with the standard deviation of $0.3 \mathrm{C}$.

Major error when measuring brightness temperature and ultimately CBT is generally related to instability of measurements, changes in Tamb due to the device heating in operation, ambient temperature changes, variations in the antenna reflection coefficient when making measurements in different parts of the body, and the presence of electromagnetic interference. An important property of the proposed device is its high stability, confirmed by a 28 -hour run. It is essential that over the course of the experiment, with selected calibration coefficients, despite variations in the front-end module temperature, the measured temperature varied slightly. Some variations of about $0.1-0.2^{\circ} \mathrm{C}$ have to do with the fact that the temperature of coaxial cable, which connects NG and radiometer, differed from the radiometer input section temperature.

Minor measurement error related to the device reflection coefficient is achieved thanks to additional heating of the load in the balance arm. Here, an astonishing feature of microwave radiometers is 
evident: despite the receiver has $25 \%$ less power delivered, the relative error in measuring power is equal to $(0.2 \mathrm{~K} / 300 \mathrm{~K}) 0.067 \%$.

To combat electromagnetic interference, structural solutions were developed, related to double shielding of front-end and antenna, filtering of each input and output wire, and the use of highselective BPF in low noise amplifier. Moreover, due to its small dimensions the device can be additionally shielded with the fabric to protect against electromagnetic interference.

Below are the main results of the experimental studies. The radiometer overall dimensions are $23 \mathrm{x}$ $31 \mathrm{x} 15 \mathrm{~mm}^{3}$, power is supplied through USB-port; power supply of the radiometer in measurement mode is $210 \mathrm{~mA}$ at a voltage of $5 \mathrm{~V}$, an increase in the SPDT module temperature due to thermal selfradiation is equal to $21^{\circ} \mathrm{C}$, operating frequency range is $3400-4100 \mathrm{MHz}$; the radiometer time constant without averaging is $0.6 \mathrm{sec}$, standard deviation $(\delta)$ in this case is $0.17^{\circ} \mathrm{C}$, with additional averaging during $4 \sec \delta$ is $0.052^{\circ} \mathrm{C}$, with averaging during $30 \mathrm{sec} \delta=0.017^{\circ} \mathrm{C}$, when there were input reflections $\mathrm{R}^{2}=0.25$ an error in measuring brightness temperature amounted to $0.2^{\circ} \mathrm{C}$, with $10^{\circ} \mathrm{C}$ variations in ambient temperature in a run during $28 \mathrm{~h}$, the error in measuring brightness temperature amounted to $0.15^{\circ} \mathrm{C}, \delta=0.058^{\circ} \mathrm{C}$.

\section{CONCLUSIONS}

The use of a new circuit of the null-balance radiometer with two matched loads, installed on the Peltier element, and applying FPAA microcircuit for post-detection processing of signals allowed creating a miniature, high-stable radiometer. The brightness temperature measurement error of such radiometer weakly depends on the ambient temperature, device temperature, and impedance of the studied area.

Bringing an additional attenuator in the circuit of reference noise signal source makes it possible to minimise the measurement error associated with variation in the radiometer front-end temperature and impedance of the studied area.

The established analytical relationships between the radiometer measurement error and electric parameters of the device components enable assessment of achieved accuracies and selection of optimal values of the circuit parameters to minimise measurement at a design stage.

Introduction of self-contained power supply and wireless communication with smartphone made it possible to use the proposed radiometer as a wearable device to monitor the CBT of internal tissues continuously during human activities. In the future, the device can be implemented in a monolithic design (Gudkov, Leushin, Vesnin, et al., 2020) and with further design improvement, such as integration into smart watches and other small wearable devices.

\section{REFERENCES}

Arunachalam, K., Maccarini, P., De Luca, V., Tognolatti, P., Bardati, F., Snow, B. \& Stauffer, P. (2011). Detection of vesicoureteral reflux using microwave radiometry-system characterization with tissue phantoms. IEEE Trans. on Biomedical Engineering, 58 (6), 1629-1636.

Cheboksarov, D., Butrov, A., Shevelev, O., Amcheslavsky, V., Pulina, N., Buntina, M. \& Sokolov, (2015). Diagnostic opportunities of noninvasive brain thermomonitoring. Anesteziologiia i Reanimatologiia, 60 (1), 66-69.

Crandall, J., Joo H. 2, Gajwani, P., Leal J., Mawhinney, D., Sterzer, F. \& Wahl, R. (2018). Measurement of brown adipose tissue activity using microwave radiometry and 18F-FDG PET/CT. Journal of Nuclear Medicine, 59 (8), 1243-1248. 
Drakopoulou, M., Moldovan, C., Toutouzas, R. \& Tousoulis, D. (2018). The role of microwave radiometry in carotid artery disease. Diagnostic and clinical prospective. Current Opinion in Pharmacology, 39, 99104.

Goodberlet, M. \& Mead, J. B. (2006). Two-load radiometer precision and accuracy. IEEE transactions on geoscience and remote sensing, 44 (1), 58-67.

Goryanin, I., Karbainov, S., Shevelev, O., Tarakanov, A., Redpath, K., Vesnin, S \& Ivanov, Yu. (2020). Passive microwave radiometry in biomedical studies. Drug Discovery Today, 25 (4), 757-763.

Groumpas E., Koutsoupidou, M., Karanasiou, I, Papageorgiou, Ch. \& Uzunoglu, N. (2019). Real-time passive brain monitoring system using near-field microwave radiometry. IEEE Trans. on Biomedical Engineering, 67 (1), 158-165.

Groumpas, E., Koutsoupidou, M., Karanasiou, I., Papageorgiou, C., and Uzunoglu, N. (2019). Real-time Passive Brain Monitoring System Using Near-Field Microwave Radiometry. IEEE Transactions on Biomedical Engineering.

Gudkov, A., Leushin, V., Sidorov, I., Vesnin, S., Porokhov, I., Sedankin, M., Agasieva, S., Chizhikov, S., Gorlacheva, E., Lazarenko, M. \& Shashurin, V. (2019). Use of multichannel microwave radiometry for functional diagnostics of the brain. Biomedical Engineering, 53 (2),108-111.

Gudkov, A., Leushin, V., Vesnin, S., Sedankin, M., Solov'ev, Yu., Agasieva, S., Chizhikov, S., Gorbachev, D. \& , S. Vidyakin (2020). Studies of a Microwave Radiometer Based on Integrated Circuits. Biomedical Engineering, 1-4.

Haines, W., Momenroodaki, P., Berry, E., Fromandi, M, Popović, Z. (2017). Wireless system for continuous monitoring of core body temperature. In: Proc. IEEE MTT-S International Microwave Symposium (IMS). 49 June 2017, Honololu, HI, USA.

Ivanov, Yu. Kozlov, A., Galiullin, R., Tatur, V., Ziborov, V., Ivanova, N., Pleshakova ,T., Vesnin, S. \& Goryanin, I. (2018). Use of microwave radiometry to monitor thermal denaturation of albumin. Frontiers in physiology, 9, 1-5.

Ivanov, Yu., Malsagova, K, Vesnin, S.,Tatur, V., Ivanova, N. \& V. Ziborov (2019). The Registration of a biomaser-like effect in an enzyme system with an RTM Sensor. Online Journal of Sensors, 2019.

Jacobsen, S., Klemetsen, Ø. \& Birkelund, Yu. (2012). Vesicoureteral reflux in young children: a study of radiometric thermometry as detection modality using an ex vivo porcine model. Physics in Medicine \& Biology, 57 (17), 5557.

Kaprin, A., Kostin, A., Andryukhin, Ivanenko, M., Popov, S., Shegai, P., Kruglov, D., Mangutov, F., Leushin,V. \& Agasieva, S. (2019). Microwave radiometry in the diagnosis of various urological diseases. Biomedical Engineering, 53 (2), 87-91.

Kublanov, V. \& Borisov, V. (2017). Biophysical evaluation of microwave radiation for functional research of the human brain. In: Proc. IFMBE (pp.1045-1048).

Livanos, N.-A., Hammal, S., Nikolopoulos, Ch., Baklezos, A., Capsalis, Ch., Koulouras, G., Charamis, P., Vardiambasis, I., Nassiopoulos, A., Kostopoulos, S., Asvestas, P., Cavouras, D. \& Siores, E. (2018). Design and interdisciplinary simulations of a hand-held device for internal-body temperature sensing using microwave radiometry. IEEE Sensors Journal, 18 (6), 2421-2433.

Maccarini, P., Shah, A., Palani, Sh., Pearce, D., Vardhan, M., Stauffer, P., Rodrigues, D., Salahi, S., Oliveira, T., Reudink, D., \& Snow, B. (2015). A novel compact microwave radiometric sensor to noninvasively track deep tissue thermal profiles. In: 2015 European Microwave Conference (EuMC) (pp. 690-693). 
Momenroodaki, P., Haines, W., Fromandi, M., P \& Popovic, Z. (2018). Noninvasive internal body temperature tracking with near-field microwave radiometry. IEEE Trans. on Microwave Theory and Techniques, 66 (5), 2535-2545.

Momenroodaki, P., Haines, W., \& Popovic, Z. (2017). Non-invasive microwave thermometry of multilayer human tissues. In: Proc. IEEE MTT-S International Microwave Symposium (IMS). 4-9 June 2017, Honololu, HI, USA.

Osipenkov, V., \& Vesnin, S. G. (1994). Microwave filters of parallel-cascade structure. IEEE transactions on microwave theory and techniques, 42 (7), 1360-1367.

Popovic, Z., Momenroodaki, P., \& Scheeler, R. (2014). Toward wearable wireless thermometers for internal body temperature measurements. IEEE Communications Magazine, 52 (10), 118-125.

Ravi, V., \& Arunachalam, K. (2019). A low noise stable radiometer front-end for passive microwave tissue thermometry. Journal of Electromagnetic Waves and Applications, 33 (6), 743-758.

Ravi, V., Sharma, A., \& Arunachalam, K. (2019). Pre-clinical testing of microwave radiometer and a pilot study on the screening inflammation of knee joints. Bioelectromagnetics, 40 (6), 402-411.

Rodrigues, D., Stauffer, P., Pereira, P., \& Maccarini, F. (2018). Microwave radiometry for noninvasive monitoring of brain temperature. In: Emerging electromagnetic technologies for brain diseases diagnostics, monitoring and therapy (pp. 87-127).

Stauffer, P., Rodriquesa, D., Salahia, S., Topsakalb, E., Oliveiraa, T., Prakasha, A., D’Isidoroa, F., Reudinkc, D., Snowc, B., \& Maccarini F. (2013). Stable microwave radiometry system for long term monitoring of deep tissue temperature. Energy-based Treatment of Tissue and Assessment VII. International Society for Optics and Photonics. San Francisco, California, United States.

Tarakanov, A.A, \& Goryanin, I. (2020). Influence of Ambient Temperature on Recording of Skin and Deep Tissue Temperature in Region of Lumbar Spine. European Journal of Molecular \&Clinical Medicine, 7 (1), $21-26$.

Toutouzas, K., Benetos, G., Koutagiar, I., Barampoutis, N., Mitropoulou, F., D. Periklis, Sfikakis, P., Alexopoulos, D., Stefanadis, Ch., Siores, E., \& Tousoulis, E. (2017). Noninvasive detection of increased carotid artery temperature in patients with coronary artery disease predicts major cardiovascular events at one year: Results from a prospective multicenter study. Atherosclerosis, 262, 25-30.

Ulaby, F.T., \& Long, D.G. (2014). Microwave Radar and Radiometric Remote Sensing. USA, University of Michigan Press: Ann Arbor.

Vesnin, S., Sedankin, M., Leushin, V., Skuratov, V., \& Nelin, I., Konovalova, A. (2019). Research of a microwave radiometer for monitoring of internal temperature of biological tissues. Eastern-European Journal of Enterprise Technologies, 4 (5), 6-15.

Vesnin, S., Turnbull, A. K., Dixon, J. M., \& Goryanin, I. (2017). Modern microwave thermometry for breast cancer. Online Journal of Molecular Imaging \& Dynamics, 7 (2).

Zinovyev, S.V. (n.d.) New medical technology-functional microwave thermography: experimental study. Presented at the 2nd International Symposium on Physics, Engineering and Technologies for Biomedicine, KnE Energy \& Physics (pp. 547-555). 